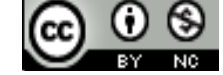

Jurnal Bimbingan Konseling Indonesia is licensed under A Creative Commons Attribution-Non Commercial 4.0 International License.

\title{
MENINGKATKAN HASIL BELAJAR IPA PESERTA DIDIK DENGAN BIMBINGAN TEMAN SEBAYA BERBASIS NILAI-NILAI HUMA BETANG
}

\author{
Muhammad Andi Setiawan ${ }^{1)}$, Agung Riadin ${ }^{2)}$ \\ 1) Universitas Muhammadiyah Palangkaraya, Palangka Raya, Indonesia \\ E-mail: andisetiawan@umpalangkaraya.ac.id \\ 2) Universitas Muhammadiyah Palangkaraya, Palangka Raya, Indonesia \\ E-mail: agungriadin@gmail.com
}

\begin{abstract}
Abstrak. Penelitian ini bertujuan untuk meningkatkan hasil belajar peserta didik dengan bantuan bimbingan teman sebaya berbasis nilai nilai huma betang. Teman sebaya merupakan unsur penting dalam pendidikan karena mereka bisa memfasilitasi teman sebaya untuk bisa lebih maju lagi. Pendekatan penelitian yang digunakan dalam penelitian ini adalah pendekatan penelitian mixed method. Strategi mixed method yang digunakan dalam penelitian ini adalah strategi transformatif sekuensial. Subjek penelitian ini yaotu peserta didik kelas 9 SMP Muhammadiyah yang berjumlah 20 orang. Pengabilan sampel dilakukan secara purposive, dan analisi data dilakukan dengan dengan analisis kualitatif dan analisis kuantitatif. Instrument pengumpulan data mengunakan tes. Berdasarkan hasil bimbingan teman sebaya berbasis huma betang di SMP Muhammadiyah palangkaraya setelah di laksanakan post test maka dapat diketahui bahwa bimbingan teman sebaya berbasis huma betang mampu meningkatkan hasl belajar peserta didik, hal ini diperkuat dengan hasil uji paired sampel t test yang menunjukan nilai t-hitung 13,78731, maka nilai t-tabel $-2,0243941<\mathrm{t}$-hitung $13,78731<\mathrm{t}$ tabel 2,0243941 yang menyatakan bahwa terdapat perbedaan rata - rata nilai pretset sebelum mengunakan bimbingan teman sebaya berbasis huma betang dengan rata - rata hasil post test setelah menggunakan bimbingan teman sebaya berbasis huma betang pada mata pelajaran IPA peserta didik
\end{abstract}

Kata Kunci: Hasil belajar IPA; bimbingan teman sebaya; huma betang

\section{PENDAHULUAN}

Pada era digital, manusia dituntut untuk semakin mampu mengembangkan dirinya sesuai dengan potensi yang dimilikinya sehingga penting bagi setiap individu memahami kemampuannya dan juga mampu mengembangkan berbagai keterampilan lainnya. Salah satu hal yang penting dalam diri individu yaitu pendidikan. Hasbullah (2012: 2) Pendidikan sangat penting dalam kehidupan manusia. Menurut (Dwi, 2020) pendidikan adalah setiap usaha, pengaruh, perlindungan dan bantuan, yang diberikan kepada anak tertuju kepada pendewasaan anak agar dapat melaksanakan tugas hidupnya sendiri. Tanpa pendidikan seorang anak tidak akan menjadi pribadi yang berkembang. Dari pendidikan formal, pendidikan dasar adalah sangat penting karena memberikan dasar perkembangan manusia. Bila pendidikan dasarnya baik, ini sangat membantu perkembangan pendidikan selanjutnya

Pembahasan mengenai fungsi tujuan pendidikan merupakan sesuatu yang penting, mengingat perjalanan setiap institusi yang memiliki visi yang jelas selalu dimulai dari tujuan (start from the end). Menurut Dewey, tujuan pendidikan ialah mengembangkan seluruh potensi yang dimiliki oleh peserta didik sehingga dapat berfungsi secara individual dan sebagai anggota masyarakat melalui penyelenggaraan pendidikan dan pengajaran yang bersifat aktif, ilmiah dan memasyarakat serta 
berdasarkan kehidupan nyata yang dapat mengembangkan jiwa, pengetahuan, rasa tanggung jawab, ketrampilan, kemauan, dan kehalusan budi pekerti. Salah satu hal yang tidak dapat terpisahkan dari Pendidikan yaitu belajar dan hasil belajar. Belajar pada hakikatnya proses interaksi terhadap semua situasi yang ada di sekitar individu Rusman (2014:1). Menurut Rusman (2016: 67) mengatakan bahwa "hasil belajar adalah sejumlah pengalaman yang diperoleh siswa yang mencakup ranah kognitif, afektif dan pisikomotorik". Oemar Hamalik (Rusman, 2016: 67) menyatakan bahwa "hasil belajar itu dapat terlihat dari terjadinya perubahan dari persepsi dan perilaku, termasuk juga pernaikan perilaku. Hasil belajar akan menggambarkan sejauh mana pengetahuan dan ilmu yang sudah di dapat peserta didik selama mengikuti kegiatan belajar mengajar di dalam kelas. Hasil belajar menunjukan kualitas pribadi peserta didik dalam memahamai dan memaknai sebuah pembelajaran.

Fenomena yang ditemui di SMP Muhammadiyah Palangkaraya nampak jelas bahwa banyak hasil belajr khususnya di mata pelajaran IPA yang masih di bawah rata-rata atau dengan kata lain peserta didik masih belum bisa tuntas dalam pembelajaran yang dilakukan. Apabila kondisi tersebut dibiarkan begitu saja maka akan berdampak pada psikis dan fisik dari peserta didik, selin itu apabila kondisi tersebut di biarkan begitu saja maka akan berdampak pada penurunan kualitas anak bangsa di kemudian hari yang anak semakin memburuk. Untuk itu perlu sebuah solusi untuk menanggani kondisi tersebut yaitu dengan bimbingan teman sebaya. Menurut Santrock, (2007). Teman Sebaya adalah anak-anak dengan tingkat kematangan atau usia yang kurang lebih sama. Pertemanan adalah suatu tingkah laku yang dihasilkan dari dua orang atau lebih yang saling mendukung. Pertemanan dapat diartikan pula sebagai hubungan antara dua orang atau lebih yang memiliki unsur-unsur seperti kecenderungan untuk menginginkan apa yang terbaik bagi satu sama lain, simpati, empati, kejujuran dalam bersikap, dan saling pengertian (Kawi, 2010).

Hubungan teman sebaya menimbulkan suatu hubungan saling percaya antra teman sebaya. Hubungan ini dapat menimbulkan suatu perilaku dimana remaja lebih percaya terhadap teman sebaya dari pada dengan orang tua, sehingga pembentukan dan pelatihan konselor sebaya atau bimbingan teman sebaya dapat menjadi suatu pilihan yang tepat dalam upaya membentengi anak atau remaja dari pengaruh negatif lingkungan.

Teman sebaya merupakan salah satu figur penting (significant others) yang sangat berperan memberi warna pada berbagai aspek perkembangan individu. Pada masa remaja, ketertarikan dan ikatan terhadap teman sebaya menjadi sangat kuat. Hal ini terbukti karena banyak remaja merasa bahwa orang dewasa tidak dapat memahaminya. Keadaan ini sering menjadikan remaja sebagai suatu kelompok yang eksklusif karena memiliki anggapan bahwa hanya sesama remaja-lah yang dapat saling memahami. Hal yang demikian merupakan peluang dan tantangan bagi konselor untuk memberikan intervensi secara tepat, salah satu diantaranya adalah dengan membangun bimbingan teman sebaya.

Usop. T. B (2011:26) Rumah tradisional dayak dikenal dengan sebutan Betang. Riswanto dkk (2017:217) Huma Betang adalah sebuah bangunan adat suku Dayak berbentuk rumah panggung yang besar dan memanjang yang terdapat di wilayah pulau Kalimantan Abubakar HM (2016:11) Istilah Huma Betang digunakan oleh bangsa Dayak berbahasa Ngaju di Kalimantan Tengah yang berarti rumah besar Nilai-nilai huma betang sebagai bentuk sebagai salah satu warisan budaya yang ada di Kalimantan tengah, dan nilai nilai tersebut dapat dipadaukan dalam bimbingan teman sebaya, apalagi melihat trend masa sekarang yang mana remaja lebih memilih kemajuan teknologi dibandung memahami warisan budaya yang dianggap ketinggalan zaman. Nilai nilai budaya huma betang yang dimaksud yaitu nilai persaudaraan, nilai belom bahadat, dan nilai hapakat basara. Berdasarkan kondisi di atas maka peneliti akan melaksanakan penelitian.

Tujuan dari penelitian ini untuk mengetahui apakah bimbingan teman sebaya berbasis nilai-nilai huma betang dapat meningkatkan hasil belajar IPA peserta didik. Penelitian ini perlu dilakukan karena melihat kondisi hasil belajar yang kurang memuaskan dan memudarnya nilai-nilai budaya 
yang ada di Kalimantan. Penelitian ini diajukan dalam skema PKDI, skema ini diberikan kepada dosen-dosen UM Palangkaraya yang memiliki kemuan untuk meneliti.

\section{METODE}

Pendekatan penelitian yang digunakan dalam penelitian ini adalah pendekatan penelitian mixed method. Menurut Bryman (Creswell, 2010) dalam mixed method untuk memperluas bahasan dengan cara menerapkan dua metode sekaligus, untuk menggunakan satu pendekatan integratif agar mampu untuk memperoleh pemahaman yang lebih baik, atau untuk menguji hasil penelitian dari pendekatan yang berbeda. Mixed method bisa saja berada dalam satu penelitian atau berada diantara sejumlah studi dalam satu program penelitian. Strategi mixed method yang digunakan dalam penelitian ini adalah strategi transformatif sekuensial. Strategi transformatif sekuensial merupakan proyek dua tahap dengan perspektif teoritis tertentu (sperti, gender, ras, teori ilmu sosial) yang turut membentuk prosedur-prosedur didalamnya. Strategi ini terdiri dari tahap pertama (baik itu kualitatif atau kuantitatif) yang diikuti oleh tahap kedua (baik itu kuantitatif ataupun kualitatif (Creswell, 2010).

Strategi transformatif sekuensial bertujuan untuk menerapkan perspektif teoretis si peneliti. Dengan diterapkannya penelitian dua tahap dalam strategi ini, peneliti diharapkan dapat menyuarakan perspektif-perspektif yang berbeda, memberikan advokasi yang lebih baik kepada partisipan, atau memahami suatu fenomena dengan lebih baik (Creswell, 2010).

Prosedur penelitian dilakukan dengan kegiatan awal yaitu penggalian data awal untuk menenukan permasalahan penelitian. Peneliti selanjunya melakukan pre test untuk mengetahui hasil belajar peserta didik yang kurang maksimal, tahap selanjutnya peneliti memberikan perlakuan berupa layanan bimbingan teman sebaya berbasis nilai huma betang dan terahir yaitu meakukan post test untuk melihat perubahan dari perlakuan yang sudah di lakukan peserta didik.
Instrument penelitian yang digunakan yaitu instrument tes hasil belajar. Instrument tersebut divalidasi terlebih dahulu untuk menghasilkan instrument yang berkualitas. Instrument tes di gunakan untuk mengali data kuantitatif. Untuk tahap kualitatif, menggunakan triangulasi sumber data (Creswell, 2010).

Populasi dalam penelitian ini yaitu peserta didik SMP Muhammadiyah palangkaraya dan sampel dalam penelitian ini aalah semua peserta didik kelas 9 yang mengikuti mata pelajaran IPA dengan jumlah 20 orang. Sampel di ambil dengan cara purposive random sampling. Analisis data dalam penelitian mixed method bisa dilakukan berdasarkan pendekatan kuantitatif (analisis angkaangka secara deskriftif dan inferensial) dan kuantitatif (deskripsi dan analisis teks atau gambar secara tematik), atau antara dua pendekatan ini (Creswell, 2010).

Moleong (2010:132) mendeskripsikan subjek penelitian sebagai informan, yang artinya orang pada latar penelitian yang dimanfaatkan untuk memberikan informasi tentang situasi dan kondisi latar penelitian. Subjek pada penelitian ini adalah Peserta Didik SMP Muhammadiyah Palangkaraya dengan pengambilan sampel secara purposive. Instrumen penelitian adalah suatu alat yang digunakan mengukur fenomena alam maupun sosial yang diamati (Sugiyono, 2014:148). Dalam mix method ini instrume yang digunakan yaitu tes dan non tes. Tes yang di pakai yaitu tes hasil belajar IPA peserta didik dan non tes yang di pakai yaitu lembar wawancara dan observasi peserta didik

Dalam penelitian ini setiap data yang terkumpul akan selalu dianalisis terus menerus, dari awal sampai akhir proses penelitian, baik itu di lapangan maupun di luar lapangan melalui penafsiran sementara terhadap semua data dan informasi yang di dapatkan pada saat penelitian. Adapun proses analisis data dilaukan dengan cara kualitatif dan kuantitatfi karena menggunakanj pendekatan Mix Method.

\section{HASIL DAN PEMBAHASAN}

Uji paired sampel $t$ test bertujuan untuk mengetahui apakah terdapat perbedaan rata - rata dua sampel yang berpasangan. Maksud dari dua 
sampel berpasangan adalah sampel/subjek yang sama tetapi memiliki dua data yang berbeda. Dalam penelitian ini sampelnya adalah seluruh peserta didik kelas 9 SMP Muhamadiyah Palangkaraya, sedangkan dua datanya adalah data pretest dan data post testnya. Hasil perhitungan uji paired sampel $t$ test dengan bantuan Microsoft Office Excel 2007 pada hasil pretest dan posttest dapat dilihat dibawah ini :

TABEL 1

UJI PAIRED SAMPEL T TEST

\begin{tabular}{|c|c|c|c|}
\hline No & Nama Siswa & Pertest & Post test \\
\hline 1 & $\mathrm{R}$ & 30 & 65 \\
\hline 2 & $\mathrm{R}$ & 65 & 80 \\
\hline 3 & $\mathrm{H}$ & 35 & 85 \\
\hline 4 & $\mathrm{~F}$ & 55 & 80 \\
\hline 5 & I & 25 & 95 \\
\hline 6 & M & 40 & 75 \\
\hline 7 & V & 40 & 85 \\
\hline 8 & FA & 40 & 80 \\
\hline 9 & $\mathrm{AI}$ & 15 & 65 \\
\hline 10 & LA & 55 & 75 \\
\hline 11 & $\mathrm{AH}$ & 20 & 65 \\
\hline 12 & $\mathrm{AB}$ & 35 & 70 \\
\hline 13 & QI & 35 & 85 \\
\hline 14 & NO & 40 & 100 \\
\hline 15 & NA & 40 & 100 \\
\hline 16 & SE & 30 & 80 \\
\hline 17 & SY & 25 & 80 \\
\hline 18 & RI & 45 & 100 \\
\hline 19 & SA & 10 & 75 \\
\hline \multirow{2}{*}{\multicolumn{2}{|c|}{$\begin{array}{l}\text { Rata-rata } \\
\text { Simp baku }\end{array}$}} & 35,75 & 81,75 \\
\hline & & 13,40414311 & 11,5022881 \\
\hline \multicolumn{2}{|c|}{ Varians } & 179,6710526 & 132,3026316 \\
\hline \multicolumn{2}{|c|}{$\mathrm{dk}$} & $\mathrm{n} 1+\mathrm{n} 2-2$ & 38 \\
\hline \multicolumn{2}{|c|}{ Selisih Rata2 } & & -46 \\
\hline \multicolumn{2}{|c|}{ Var1/N1 } & & 8,983553 \\
\hline \multicolumn{2}{|c|}{ Var2/N2 } & & 6,615132 \\
\hline \multicolumn{2}{|c|}{ Koef Korelasi } & & 0,289736 \\
\hline \multicolumn{2}{|c|}{$2 *$ Koef Korelasi } & & 0,579473 \\
\hline & & 2,997258 \\
\hline \multicolumn{2}{|c|}{$\begin{array}{l}\text { simp baku/ akar N1 } \\
\text { simp baku/ akar N2 }\end{array}$} & & 2,57199 \\
\hline
\end{tabular}

Berdasarkan hasil uji paired sampel $t$ test menggunakan Microsoft Office Excel 2007 , didapatkan nilai $\mathrm{t}$ tabel $-2,0243941<\mathrm{t}_{\text {hitung }}$ $13,78731>t$ tabel 2,0243941 dengan demikian, dapat disimpulkan bahwa bimbingan teman sebaya berbasis huma betang dapat meningkatkan hasil belajar IPA peserta didik.

Berdasarkan hasil bimbingan teman sebaya berbasis huma betang di SMP Muhammadiyah palangkaraya kegiatan awal yang dilakukan yaitu melakukan tes berupa pre test bagi peserta didik, hasil pre test sebelum menggunakan bimbingan teman sebaya berbasis huma betang hanya terdapat 1 orang peserta didik yang memenuhi kelulusan individual berdasarkan KKM. Selanjutnya, setelah penggunaan bimbingan teman sebaya berbasis huma betang dilakukan tes berupa post test, hasil post test terdapat 20 peserta didik yang memenuhi kelulusan individual. Berdasarkan hal tersebut, bimbingan teman sebaya berbasis huma betang mampu meningkatkan hasl belajar peserta didik, hal ini diperkuat dengan hasil uji paired sampel t test yang menunjukan nilai $t_{\text {hitung }} 13,78731$, maka nilai $t$ tabel $-2,0243941<t_{\text {hitung }} 13,78731<t_{\text {tabel }} 2,0243941$ yang menyatakan bahwa terdapat perbedaan rata rata nilai pre test sebelum mengunakan bimbingan teman sebaya berbasis huma betang dengan rata rata hasil post test setelah menggunakan bimbingan teman sebaya berbasis huma betang pada mata pelajaran IPA peserta didik dengan selisih rata-rata 46 dari 20 peserta didik .

\section{KESIMPULAN}

Penelitian ini memberikan sumbangan positif dalam bimbingan dan konseling dimana nilai nilai budaya huma betang yang berasal dari Kalimantan Tengah dapat di padukan dalam pemberian layanan bimbingan dan konseling. Hasil penelitian menunjukan bahwa bimbingan teman sebaya berbasis nilai-nilai huma betang dapat meningkatkan hasil belajar IPA peserta didik. Hasil analisis uji paired sampel $t$ test menggunakan Microsoft Office Excel 2007 , didapatkan nilai $t_{\text {tabel }}$ $-2,0243941<t_{\text {hitung }} 13,78731>\mathrm{t}$ tabel 2,0243941 dengan demikian, dapat disimpulkan bahwa bimbingan teman sebaya berbasis huma betang dapat meningkatkan hasil belajar IPA peserta didik.

\section{DAFTAR PUSTAKA}

Abubakar HM. (2016). Huma Betang Dan Aktualisasi Nilai Kearifan Lokal Dalam Budaya Dayak. 259 Vol. 1, No. 2, Juli - Desember

Creswell, J. W. (2010). Research design: pendekatan kualitatif, kuantitatif, dan mixed. Yogjakarta: PT Pustaka Pelajar.

Dwi, Z. (2020). Pengaruh Sistem Full Day School Terhadap Motivasi Belajar Dan Pembentukan Karakter Siswa Di Smp It At- Taqwa Surabaya. Inspirasi Manajemen Pendidikan, 8, 27-40.

Mudjito et all,. (2012). Pendidikan Inklusif. Jakarta: Baduose. Moleong, L. J. (2010). Metodologi Penelitian Kualitatif. Bandung: Remaja Rosda karya. 
Riswanto, D., Mappiare-AT, A., \& Irtadji, M. (2017). Kompetensi multikultural konselor pada kebudayaan suku dayak kalimantan tengah. Jomsign: Journal of Multicultural Studies in Guidance and Counseling, 1(2), 215-226.

Rusman. (2014). Pembelajaran Tematik Terpadu. Bandung: Alfabeta.

Rusman. (2016) Model-model Pembelajaran. Jakarta: Kharisma Putra Utama.

Santrock. (2007). Perkembangan Anak. Jilid 1 Edisi kesebelas. Jakarta: PT. Erlangga.

Sunaryo. (2004). Psikologi Untuk Pendidikan. Jakarta: EGC.

Soekanto, Soerjono. (2001). Hukum Adat Indonesia. Jakarta: PT. Raja Grafindo. Persada.

Sugiyo. (2011). Manajemen Bimbingan dan Konseling di Sekolah. Semarang: Widya Karya.

Sugiyono. (2014). Metodelogi Penelitian Kuantitatif Kualitatif dan $R \& D$. Bandung; Alfabeta.

Sugiyono. (2011) Metode Penelitian Administrasi. Bandung: Alfabeta.

Slameto. (2012). Penelitian dan Inovasi Pendidikan. Semarang: Widya Sari Press.

Tohirin. (2009). Bimbingan dan Konseling di Sekolah dan Madrasah (Berbasis Integrasi). Jakarta: Rajawali Pers.

Usop, T. B. (2011). Kearifan Lokal Dalam Arsitektur Kalimantan Tengah Yang Berkesinambungan. Jurnal Prespektif Aarsitektur Vol. 06 No. 01 2011, 25-32. 